\title{
EFFECT OF HYDROLYSIS TIME ON RADIOCHEMICAL AND CHEMICAL PURITY OF 2- $\left[{ }^{18} \mathrm{~F}\right]$ FLUORO-2-DEOXY-D-GLUCOSE
}

\author{
PAWEŁ WAŚNIOWSKI ${ }^{1,2 *}$, JOLANTA CZUCZEJKO ${ }^{2,3}$, NATALIA PIEKUŚ-SŁOMKA ${ }^{1}$, \\ EWELINA WĘDROWSKA ${ }^{4}$, MATEUSZ WĘDROWSKI ${ }^{2,5}$, MICHAL CHUCHRA $^{2}$, \\ STANISŁAW SOBIAK ${ }^{1}$, and BOGDAN MAŁKOWSKI ${ }^{2,5}$
}

${ }^{1}$ Department of Inorganic and Analytical Chemistry, Collegium Medicum in Bydgoszcz, Nicolaus

Copernicus University in Torun, ul. Jagiellonska 13-15, 85-067 Bydgoszcz, Poland

${ }^{2}$ Nuclear Medicine Department, Oncology Centre prof. Franciszek Lukaszczyk Memorial, ul. dr I. Romanowskiej 2, 85-796 Bydgoszcz, Poland

${ }^{3}$ Department of Psychiatry, Collegium Medicum in Bydgoszcz, Nicolaus Copernicus University in Torun, ul. Jagiellonska 13-15, 85-067 Bydgoszcz, Poland

${ }^{4}$ Department of Lung Diseases, Neoplasms and Tuberculosis, Collegium Medicum in Bydgoszcz, Nicolaus

Copernicus University in Torun, ul. Jagiellonska 13-15, 85-067 Bydgoszcz, Poland

${ }^{5}$ Department of Diagnostic Imaging, Collegium Medicum in Bydgoszcz, Nicolaus Copernicus University in Torun, ul. Jagiellonska 13-15, 85-067 Bydgoszcz, Poland

\begin{abstract}
The basis for the release of $\left[{ }^{18} \mathrm{~F}\right] \mathrm{FDG}$ for use is the results of quality control studies within the scope of the specification, based on the recommendations of the Pharmacopoeia (FP XI and Ph. Eur. IX). The object of this study is the influence of the $\left[{ }^{18} \mathrm{~F}\right] \mathrm{FDG}$ hydrolysis time on the quality parameters, with particular regard to radiochemical purity. The synthesis was performed at three different hydrolysis times: 8,10 , and 12 minutes. 21 syntheses were performed for each time. For the $\left[{ }^{18} \mathrm{~F}\right] \mathrm{FDG}$ solution, the radiochemical purity was assessed with the TLC method, the radiochemical and chemical purity with the HPLC method, and the $\mathrm{pH}$ value with the potentiometric method. Extending the hydrolysis time significantly increased the radiochemical purity of the final $\left[{ }^{18} \mathrm{~F}\right] \mathrm{FDG}$ product, improving its quality parameters (mainly reducing the amount of acetyl derivatives of $\left[{ }^{18} \mathrm{~F}\right] \mathrm{FDG}$ while maintaining chemical purity and $\mathrm{pH}$ value but with a slight loss of activity. A result at the accept/reject limit may negatively affect the stability test. Increasing the radiochemical purity allows us to avoid the invalidation of this test due to the influence of device measurement error and possible operator error (human). Minimizing contamination reduces impact GLUT independent tumor cell accumulation of $\left[{ }^{18} \mathrm{~F}\right] \mathrm{FDG}$, which its detail of character is still unknown. The possibility of a false-positive result in an imaging examination and minimizes the impact of radiation from contaminants on the patient's tissues. Additional biological studies should be performed to investigate the metabolism of the acetyl derivative of $\left[{ }^{18} \mathrm{~F}\right] \mathrm{FDG}$.
\end{abstract}

Keywords: $\left[{ }^{18} \mathrm{~F}\right] \mathrm{FDG}$ synthesis, hydrolysis time, PET

Positron emission tomography (PET) is an emission method. Unlike absorption methods, in the PET method, the image is generated on the basis of information sent from the object, which requires the source of this information to be placed in the object under study. The information carrier in PET is gamma radiation quanta, while the radiation source is a radiopharmaceutical accumulated in the body (1-3).

Cancer cells create their microenvironment, in which a different cellular metabolism functions. They prefer anaerobic glycolysis even with sufficient oxygen. Anaerobic glycolysis, although it provides a small amount of ATP, is a source of intermediate products needed, among other things, for the synthesis of nucleic acids, proteins, and lipids. Cancer cells compensate for the choice of a less efficient process by a 124 -fold increase in the intensity of anaerobic glycolysis. Increasing the intensity of this process increases the formation of intermediate products, maintaining the supply of energy and nutrients at an appropriate level (4-6).

Increased glucose metabolism and the associated different pathway of $\left[{ }^{18} \mathrm{~F}\right] \mathrm{FDG}$ metabolism and

* Corresponding author: e-mail: wasniowskip@co.bydgoszcz.pl 
accumulation in neoplastic cells is used in the process of diagnosing malignant growth foci with positron emission tomography (7).

Glucose labeled with the fluorine ${ }^{18} \mathrm{~F}$ isotope is one of the most frequently used radiopharmaceuticals in oncological diagnostics using PET technology.

2- $\left[{ }^{18} \mathrm{~F}\right]$ fluoro-2-deoxy-D-glucose is an effective imaging agent for various types of tumors characterized by increased glucose metabolism. The development of effective methods of synthesis performed with the use of automated radiochemical modules, the relatively long half-life of the ${ }^{18} \mathrm{~F}$ fluorine isotope, and the effectiveness of cancer imaging contributed to the widespread use and commercialization of this radiotracer (8-10).

The individual steps of the synthesis and purification of $\left[{ }^{18} \mathrm{~F}\right] \mathrm{FDG}$ are aimed at producing a radiopharmaceutical of the highest purity, meeting all the quality requirements resulting from the recommendations of the Polish Pharmacopoeia (FP XI) and/ or the European Pharmacopoeia (Ph. Eur. IX). The method of synthesis and purification, with a properly programmed automatic procedure, which is important for the amount of reagents added, temperature, and duration of individual stages, has an influence on the amount of radiochemical and chemical contamination and the correct $\mathrm{pH}$ value of the produced radiopharmaceutical.

\section{EXPERIMENTAL}

\section{Materials and methods Automatic radiosynthesis on the Explora FDG4 module}

The SIEMENS Eclipse $11 \mathrm{MeV}$ Cyclotron was used to produce the ${ }^{18} \mathrm{~F}$ isotope. The target material for the production was $2.4 \mathrm{~mL}$ of water enriched in the isotope of oxygen $\left[{ }^{18} \mathrm{O}\right] \mathrm{H}_{2} \mathrm{O}$. The reaction that occurred during the conversion of fluorine to ${ }^{18} \mathrm{~F}^{-}$was ${ }^{18} \mathrm{O}(\mathrm{p}, \mathrm{n}){ }^{18} \mathrm{~F}$. At the end of the bombardment (EOB, $\mathrm{t}=0$ ) the amount of the ${ }^{18} \mathrm{~F}$ fluorine isotope averaged $120 \mathrm{GBq}$. The produced ${ }^{18} \mathrm{~F}$ - ion in $2.4 \mathrm{~mL}$ of an aqueous solution was transported from the cyclotron target to the Explora $\mathrm{FDG}_{4}$ synthesis module by a Teflon capillary using argon as a push gas.

In order to separate the ${ }^{18} \mathrm{~F}^{-}$ion from impurities reducing its activity (water, metal ions from the cyclotron target), the aqueous solution of fluoride was passed through the ion exchange column Preconditioned Sep-PAK Light QMA Cartridge with $\mathrm{CO}_{3}{ }^{2-}$ - as counterions, filled with an organic polymer connected to hydrocarbon chains containing at their terminus groups $-\mathrm{NR}^{3+}$ derived from quaternary ammonium salts. The $\mathrm{CO}_{3}{ }^{2-}$ carbonate anions are counterions that balance the positive charge of the end of the hydrocarbon chain.

There was an anion exchange on the column. Fluorine was retained on the column beds, and the water with metal ions and $\mathrm{CO}_{3}{ }^{2-}$ was removed to the reclaimed water vessel.

The fluoride anion from the QMA cartridge was recovered by elution with an aqueous-acetonitrile solution of Kryptofix (Kryptand 222) and $\mathrm{K}_{2} \mathrm{CO}_{3}(0.9 \mathrm{~mL})$.

During elution, residual water gets into the reaction vessel and needs to be removed. The acetonitrile $(2.2 \mathrm{~mL})$ added to the reaction vessel forms an azeotropic mixture with water. The reaction mixture is evaporated at $110^{\circ} \mathrm{C}$ until the solvents $\left(\mathrm{H}_{2} \mathrm{O}\right.$ and $\mathrm{CH}_{3} \mathrm{CN}$ ) are completely eliminated in a stream of inert gas - nitrogen of purity 5.0. With a completely dry reaction vessel, the temperature reading (from the software of the Explora $\mathrm{FDG}_{4}$ module) rises above $110^{\circ} \mathrm{C}$. At this point, the evaporation process of the contents of the reaction vessel is complete. The process is repeated twice and lasts from 5 to 10 minutes.

The precursor used in the production of $\left[{ }^{18} \mathrm{~F}\right]$ FDG was mannose triflate (1,3,4,6-tetra-O-acetyl2 -O-trifluoromethanesulfonyl- $\beta$-D-mannopyranose). The precursor used has a leaving group in position 2 - triflate (triflate), and in position 1,3,4,6 protecting groups - acetyl. During the nucleophilic substitution reaction, the triflate group is replaced with the fluorine isotope ${ }^{18} \mathrm{~F}$ and the spatial arrangement of the sugar C2 carbon atom substituents is inverted, according to the Sn2 nucleophilic bimolecular substitution mechanism. The labeling temperature was $90^{\circ} \mathrm{C}$, and the process took 1 minute. The amount of mannose triflate used for the reaction is $50 \mathrm{mg} \pm 5 \%$ per run in a volume of $2.2 \mathrm{~mL}$ of acetonitrile. After the labeling is complete, the acetonitrile is evaporated off. The evaporation time was on average 5 minutes. This process takes place for greater efficiency under a stream of nitrogen with a purity of 5.0-6.0.

The final step in the synthesis was the removal of the acetyl protecting groups. The acid hydrolysis of tetra-acetyl $\left[{ }^{18} \mathrm{~F}\right] \mathrm{FDG}$ is carried out with $2.5 \mathrm{~mL}$ of $1 \mathrm{~N}$ hydrochloric acid added to a reaction vessel that has been heated to $120^{\circ} \mathrm{C}$. The reaction was performed at three different times of 8, 10, and 12 minutes. 21 syntheses were performed for each time. Under these conditions, the acetyl groups are detached and converted to acetic acid. At the point of decoupling, hydrogen is attached to form $\mathrm{OH}$ groups.

Purification of the crude end product was accomplished by transferring the reaction mixture through a series of columns. The cation exchange column removed $\mathrm{K}^{+} / \mathrm{K} 222$ complexes, the ion retarding 
cartridge neutralized the acid, the neutral alumina column removed the unreacted ${ }^{18} \mathrm{~F}^{-}$anions, the $\mathrm{C} 18$ cartridge removed the tetra-acetyl $\left[{ }^{18} \mathrm{~F}\right] \mathrm{FDG}$.

\section{Quality control - method validation The validation of a method for determination of radiochemical purity of ${ }^{18} F$ FDG - the TLC method}

The TLC method for determining the radiochemical purity was validated according to ICH (The International Council for Harmonisation of Technical Requirements for Pharmaceuticals for Human Use) standards.

The validation of the specificity and reproducibility parameters was carried out on three series of 18F-FDG. The method was consistent with the pharmacopoeial monograph: FP XI FDG: 07/2008: 1325.

The equipment used to perform the determination of radiochemical purity of $\left[{ }^{18} \mathrm{~F}\right] \mathrm{FDG}$ was a radio TLC scanner (miniGITA TLC; Elysia-Raytest, Germany). TLC plates were aluminum plates $(10 \times 2 \mathrm{~cm})$ pre-coated with Silica 60 F254 from Merck. TLC mobile phase was a freshly made mixture of acetonitrile and water $(95: 5 \mathrm{v} / \mathrm{v})$. Samples (the size of the spot was $5 \mu \mathrm{L}$ ) were applied $1 \mathrm{~cm}$ above the bottom of the plate. The plates were developed in a glass chamber $(10 \times 20 \mathrm{~cm})$. The vapor space of the chamber was saturated for $30 \mathrm{~min}$ before TLC plates were developed. The migration distance was $8 \mathrm{~cm}$. After the development, the TLC plates were dried in an air stream and were put on the TLC scanner. Radiochemical purity was defined as the percentage of the radioactivity present in the radionuclide of the specified chemical form of interest (free ${ }^{18} \mathrm{~F},\left[{ }^{18} \mathrm{~F}\right] \mathrm{FDG}$, acetylated $\left[{ }^{18} \mathrm{~F}\right] \mathrm{FDG}$ ) from the total radioactivity of the radionuclide present in $\mathrm{Rf}$ preparation, respectively.

\section{Reproducibility}

Reproducibility was performed under the same operating conditions on the same day, comparing the results obtained on three different days (three different series) and by two different analysts. From the obtained results, arithmetic means $(\bar{X})$, as well as standard deviation (s) and coefficient of variation $(\% \mathrm{CV})$ between series and between analysts, were calculated:

$$
C V(\%)=s / \bar{X} \times 100 \%
$$

\section{Specificity}

The specificity of the method was performed by injecting standard solutions (standards from
ABX advanced biochemical compounds; Radeberg, Germany): 2-fluoro-2-deoxy-D-glucose (FDG), 2-fluoro-2-deoxy-D-mannose (FDM) and comparing the retention time of each standard. 3 lots of $\left[{ }^{18} \mathrm{~F}\right]$ FDG (in 3 replications) were also used for specificity tests to estimate the retention time of $\left[{ }^{18} \mathrm{~F}\right] \mathrm{FDG}$ and impurities.

All set criteria for reproducibility (the method showed a coefficient of variation below 5\%) and specificity (peaks kept well resolved; method can separate the component of interest from other components in the product, the peaks are characteristic for standards) of the TLC method were met. The TLC method was found to be reproducible and specific for $\left[{ }^{18} \mathrm{~F}\right]$ FDG determination.

\section{The validation of a method for determination of chemical and radiochemical purity of ${ }^{18}$ F FDG - the HPLC method}

The chromatographic method for determining the chemical and radiochemical purity was validated according to ICH (The International Council for Harmonisation of Technical Requirements for Pharmaceuticals for Human Use) standards.

The validation of the specificity and reproducibility parameters was carried out on five series of $\left[{ }^{18} \mathrm{~F}\right] \mathrm{FDG}$. The method was consistent with the pharmacopoeial monograph: FP XI FDG: 07/2008: 1325.

The equipment used to perform determination was a high-performance liquid chromatograph - Shimadzu Prominence UFLC, LC20 AD pump, which was equipped with both the RayTest Gaby Star gamma radiation detector and the DECADE II electrochemical detector. The separation was obtained using a strong anion exchange column (DIONEX CarboPac PA10 um size pore; $4 \times 250 \mathrm{~mm}$ with precolumn Dionex Amino Trap $4 \times 50 \mathrm{~mm}$ ) and mobile phase $0.1 \mathrm{M} \mathrm{NaOH}$ solution. The volume of the injection was $10 \mu \mathrm{L}$ and the flow rate of the mobile phase was set at $1.0 \mathrm{~mL} / \mathrm{min}$, with a total run of $25 \mathrm{~min}$ utes, at $25^{\circ} \mathrm{C}$.

\section{Reproducibility}

Reproducibility was performed under the same operating conditions on the same day, comparing the results obtained on five different days (five different series) and by two different analysts. From the obtained results, arithmetic means $(\bar{X})$, as well as standard deviation (s) and coefficient of variation $(\% \mathrm{CV})$ between series and between analysts, were calculated:

$$
C V(\%)=s / \bar{X} \times 100 \%
$$




\section{Specificity}

In order to demonstrate the specificity of the method, the analysis was performed for a series of standard solutions (standards from ABX advanced biochemical compounds; Radeberg, Germany): 2-fluoro-2-deoxy-D-glucose (FDG), 2-chloro-2-deoxyD-glucose (CIDG), 2-fluoro-2-deoxy-D-mannose (FDM). Sodium chloride and 3 lots of $\left[{ }^{18} \mathrm{~F}\right] \mathrm{FDG}$ (in 3 replications) were also used for specificity tests.

All set criteria for reproducibility (the method showed a coefficient of variation below 5\%) and specificity (peaks kept well resolved; method can separate the component of interest from other components in the product) of the HPLC method were met. The HPLC method was found to be reproducible and specific for $\left[{ }^{18} \mathrm{~F}\right] \mathrm{FDG}$ determination.

\section{Quality control}

The radiochemical purity of the $\left[{ }^{18} \mathrm{~F}\right] \mathrm{FDG}$ solution was assessed on the basis of ascending TLC, using strips $(10 \times 2 \mathrm{~cm})$ of Silica Gel. A Raytest gamma radiation detector with a NaI 3"x3" scintillation crystal was used to assess the radiometric purity. An acetonitrile/water solution (Acetonitrile for HPLC; SIGMA, water for HPLC; POCH) prepared in a ratio of $95 / 5$ was used as the mobile phase. After applying the $\left[{ }^{18} \mathrm{~F}\right] \mathrm{FDG}$ sample to the starting side on the TLC strip and drying the applied spot, the strip was placed in a closed glass chromatography chamber, in which stretching took place in a mobile phase solution. The solvent front reached $8 \mathrm{~cm}$ from the starting point. After removal from the chamber, the strips were air-dried and then placed on a sliding radiometric detector table that recorded the decay of the identified isotopes over time. Based on the results of the analyses, it was possible to determine the percentage of fluorine-18 in the form of $2-\left[{ }^{18} \mathrm{~F}\right]$ fluoro-2-deoxy-D-glucose and 2-[ $\left.{ }^{18} \mathrm{~F}\right]$ fluoro-2-deoxyD-mannose and radiochemical impurities: fluorine-18 in the form of fluoride and partially or fully acetylated derivatives of 2- $\left[{ }^{18} \mathrm{~F}\right]$ fluoro-2-deoxy-D-glucose and $2-\left[{ }^{18} \mathrm{~F}\right]$ fluoro-2-deoxy-D-mannose.

\section{Limit values of radiochemical purity tested by $T L C$ :}

a. fluorine-18 in the form of 2-[18 F]fluoro-2-deoxy-D-glucose and 2-[18 F]fluoro-2-deoxy-D-mannose not less than $95 \%$ of the total radioactivity of fluorine-18.

b. fluorine-18 in the form of fluoride and partially or fully acetylated derivatives of $2-\left[{ }^{18} \mathrm{~F}\right]$ fluoro-2-deoxy-D-glucose and 2- $\left.{ }^{18} \mathrm{~F}\right]$ fluoro-2-deoxy$D$-mannose not more than $5 \%$ of total radioactivity of fluorine-18.
The radiochemical and chemical purity of the $\left[{ }^{18} \mathrm{~F}\right]$ FDG solution was tested by HPLC (SHIMADZU multi-module device) with the use of detectors connected in series - radiometric $(\mathrm{NaI} 3 \times 3$ inch scintillation crystal) by Raytest and electrochemical Decade II (gold electrode, by Antec). Ion-exchange chromatography columns dedicated to the separation of carbohydrates - Dionex CarobPac $(250 \times 4 ; 10 \mu \mathrm{m})$ with pre-column retaining amino acids - Dionex $(50 \times 4)$ were used for the analysis. Both columns were in a thermostatic oven which was kept at a constant temperature of $25^{\circ} \mathrm{C}$. The mobile phase was $0.1 \mathrm{M}$ aqueous $\mathrm{NaOH}$ solution, prepared from $50 \%$ $\mathrm{NaOH}$ solution (SIGMA) and HPLC water $(\mathrm{POCH})$, degassed with helium both during column conditioning and analysis. The analysis lasted 25 minutes. The injection volume was $10 \mu \mathrm{L}$. After the analysis was completed, the chromatograms obtained from both detectors were integrated using LabSolution software. The radiochemical purity was assessed on the chromatogram obtained from the radiometric detector as the percentage of fluorine-18 in the form of 2-[ $\left.{ }^{18} \mathrm{~F}\right]$ fluoro-2-deoxy-D-glucose and 2- $\left[{ }^{18} \mathrm{~F}\right]$ fluoro-2-deoxy-D-mannose. The chemical purity, i.e. the content of 2-chloro-2-deoxy-D-glucose (CIDG), was assessed on the chromatogram obtained from the electrochemical detector.

c. Limit values of radiochemical purity tested by HPLC: fluorine-18 in the form of 2-[18F]fluoro2-deoxy-D-glucose and 2-[18F]fluoro-2-deoxy-Dmannose not less than $95 \%$ of the total radioactivity of fluorine-18.

d. Limit values of chemical purity tested by HPLC: 2-chloro-2-deoxy-D-glucose (CIDG) content of $\leq 0.5 \mathrm{mg} / \mathrm{V}$; where $V=5 \mathrm{~mL}$, i.e. $\leq 0.1 \mathrm{mg} / \mathrm{mL}$.

The $\mathrm{pH}$ value of the $\left[{ }^{18} \mathrm{~F}\right] \mathrm{FDG}$ solution was tested with the potentiometric method using a SI Analytics microelectrode and a Martini Mi150 pH meter, by immersing the electrode directly in the solution of the radiopharmaceutical to be tested. Before starting the work, the $\mathrm{pH}$-meter was calibrated with two Millwaukee $\mathrm{pH} 4.1$ and 7.1 buffer solutions. The $\mathrm{pH}$ was read after its value stabilized on the instrument display.

$$
\text { e. Limit values: } p H 4.5 \text { to } 8.5 \text {. }
$$

\section{Statistical analysis}

Statistical analysis was performed using STATISTICA $^{\text {TM }} 13.1$ software (DELL Inc., United States). The normality of data distribution was tested using the Shapiro-Wilk test. Levene's test was used to determine the homogeneity of variance between groups. All parameters demonstrate non-normal distribution or heterogeneity of variance. The data 
Table 1 . The influence of hydrolysis time on chemical/radiochemical purity of $\left[{ }^{18} \mathrm{~F}\right] \mathrm{FDG}$ and $\mathrm{pH}$.

\begin{tabular}{|c|c|c|c|c|c|}
\hline \multirow[b]{3}{*}{ Parameter (method) } & \multirow{3}{*}{$\begin{array}{l}\text { Limits of } \\
\text { acceptance }\end{array}$} & \multicolumn{3}{|c|}{ Results: Hydrolysis time [min] } & \multirow[b]{3}{*}{$\mathrm{p}$} \\
\hline & & $8(\mathrm{n}=21)$ & $10(\mathrm{n}=21)$ & $12(\mathrm{n}=21)$ & \\
\hline & & $\begin{array}{c}\text { Median } \\
\text { IQR } \\
\text { Min-Max }\end{array}$ & $\begin{array}{c}\text { Median } \\
\text { IQR } \\
\text { Min-Max }\end{array}$ & $\begin{array}{c}\text { Median } \\
\text { IQR } \\
\text { Min-Max }\end{array}$ & \\
\hline$\left[{ }^{18} \mathrm{~F}\right] \mathrm{FDG}$ (TLC) [\%] & $\geq 95$ & $\begin{array}{c}96.05 \dagger \\
95.69 ; 96.34 \\
(95.19-97.75)\end{array}$ & $\begin{array}{c}98.23 \dagger \\
97.71 ; 98.63 \\
(97.11-100.00)\end{array}$ & $\begin{array}{c}99.65 \dagger \\
99.06 ; 99.75 \\
(98.79 ; 100.00)\end{array}$ & $<0.001$ \\
\hline Acetyl (TLC) [\%] & $\leq 5$ & $\begin{array}{c}3.81 \dagger \\
3.51 ; 4.19 \\
(2.34-4.78)\end{array}$ & $\begin{array}{c}1.80 \dagger \\
1.26 ; 2.01 \\
(0.00-2.74)\end{array}$ & $\begin{array}{c}0.35 \dagger \\
0.22 ; 0.75 \\
(0.00-1.12)\end{array}$ & $<0.001$ \\
\hline$\left[{ }^{18} \mathrm{~F}\right] \mathrm{FDG}$ (HPLC) [\%] & $\geq 95$ & $\begin{array}{c}99.681 \\
99.539 ; 99.755 \\
(99.120-100.00)\end{array}$ & $\begin{array}{c}99.616 \\
99.529 ; 99.704 \\
(99.263-99.822)\end{array}$ & $\begin{array}{c}99.678 \\
99.601 ; 99.784 \\
(99.293-99.874)\end{array}$ & 0.374 \\
\hline ClDG (HPLC) $[\mathrm{mg} / \mathrm{mL}]$ & $\leq 0,1$ & $\begin{array}{c}0.001 \\
0.001 ; 0.002 \\
(0.001-0.002)\end{array}$ & $\begin{array}{c}0.001 \\
0.001 ; 0.001 \\
(0.001-0.002)\end{array}$ & $\begin{array}{c}0.001 \\
0.001 ; 0.001 \\
(0.000-0.005)\end{array}$ & 0.896 \\
\hline $\mathrm{pH}\left[{ }^{18} \mathrm{~F}\right] \mathrm{FDG}$ & $4.5-7.1$ & $\begin{array}{c}6.85+t \\
6.68 ; 7.11 \\
(6.40-7.96)\end{array}$ & $\begin{array}{c}5.95 \dagger \\
5.75 ; 6.02 \\
(5.50-7.00)\end{array}$ & $\begin{array}{c}6.12 \ddagger \\
6.03 ; 6.21 \\
(5.92-6.65)\end{array}$ & $<0.001$ \\
\hline
\end{tabular}

n: number of samples, Me: median, IQR: interquartile range,

p: p-value (obtained with the Kruskal-Wallis test)

$\dagger+$ result of multiple comparisons of mean ranks - $\mathrm{p}<0.05$

are expressed as a median $(\mathrm{Me})$, interquartile range (IQR), and minimum-maximum value (Min-Max). The groups were compared using the Kruskal-Wallis test. A 0.05 level of significance was used. Multiple comparisons of mean ranks for all groups were performed for variability with a p-value lower than the level of significance.

\section{RESULTS}

The reaction was performed for three different hydrolysis times of 8, 10, and 12 minutes. Each type of synthesis was performed 21 times. A general summary of results is collected in Table 1 .

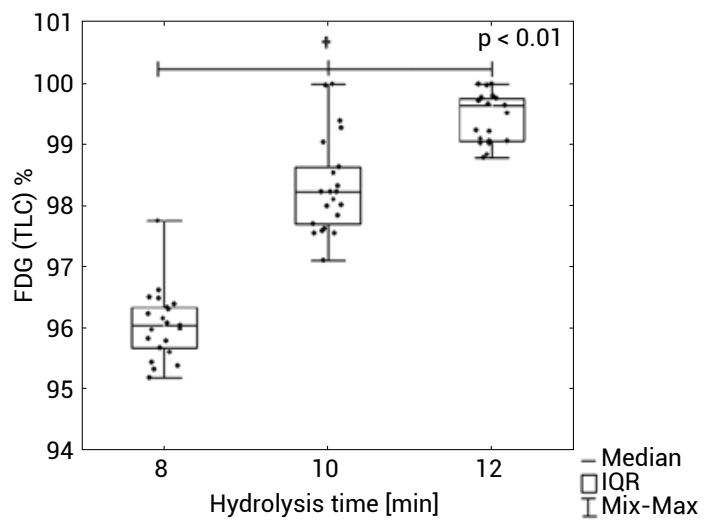

Figure 1 . The influence of hydrolysis time on radiochemical purity of $\left[{ }^{18} \mathrm{~F}\right] \mathrm{FDG}[\%]$; TLC method.

\section{Assessment of radiochemical purity} of $\left[{ }^{18}\right.$ F $]$ FDG solution by TLC

The TLC results obtained during 8,10 , and 12 minutes of hydrolysis are within the limits (Table 1). Extending the hydrolysis time from 8 to 10 and 12 minutes caused an increase in the percentage of fluorine-18 in the form of $2-\left[{ }^{18} \mathrm{~F}\right]$ fluoro-2-deoxy-D-glucose and 2-[ $\left[{ }^{18} \mathrm{~F}\right]$ fluoro-2-deoxyD-mannose (Figure 1), as well as a decrease in the percentage of fluoride-18 as fluoride and partially or fully acetylated derivatives of $2-\left[{ }^{18} \mathrm{~F}\right]$-fluoro2-deoxy-D-glucose and 2-[ $\left.{ }^{18} \mathrm{~F}\right]$-fluoro-2-deoxy-Dmannose (Figure 2). All results are statistically significant.

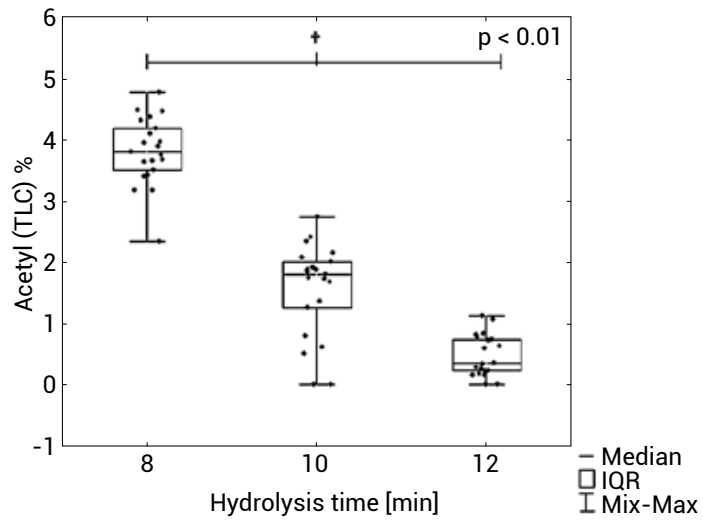

Figure 2. The influence of hydrolysis time on acetyl-derivatives of $\left[{ }^{18} \mathrm{~F}\right]$ FDG concentration $[\%]$; TLC method. 


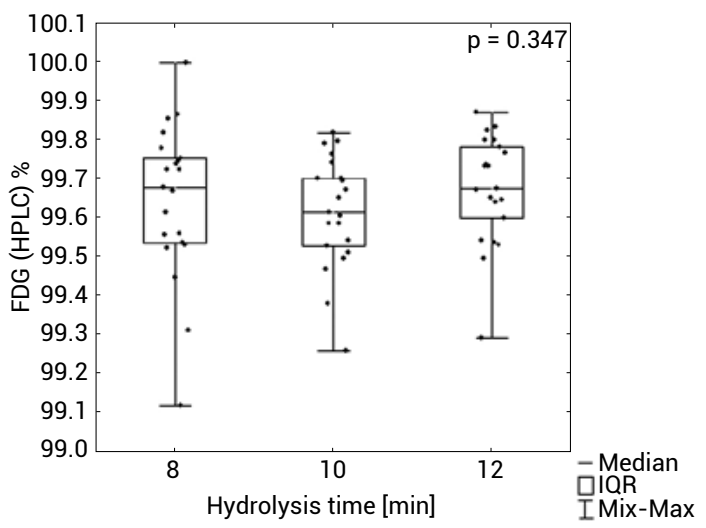

Figure 3. The influence of hydrolysis time on radiochemical purity of $\left[{ }^{18} \mathrm{~F}\right] \mathrm{FDG}[\%]$; HPLC method.

\section{Assessment of radiochemical and chemical purity of [18F]FDG solution by HPLC}

The HPLC results obtained during 8, 10, and 12 minutes of hydrolysis are within the limits (Table 1). Extending the hydrolysis time from 8 to 10 and 12 minutes did not affect the radiochemical purity as a percentage of fluorine-18 in the form of 2- $\left[{ }^{18} \mathrm{~F}\right]$ fluoro-2-deoxy-D-glucose and 2- $\left[{ }^{18} \mathrm{~F}\right]$ fluoro2-deoxy- D-mannose, nor the chemical purity, in the form of CIDG content (Figure 3, Figure 4).

\section{DISCUSSION}

The individual stages of $\left[{ }^{18} \mathrm{~F}\right] \mathrm{FDG}$ synthesis and purification are aimed at producing a radiopharmaceutical of the highest purity, meeting all the quality requirements of the Polish Pharmacopoeia (FP XI) and/or the European Pharmacopoeia (Ph. Eur. IX). The method of synthesis and purification, with a properly programmed automatic procedure, which is important for the amount of added reagents, temperature, and duration of individual stages, affects the amount of radiochemical and chemical

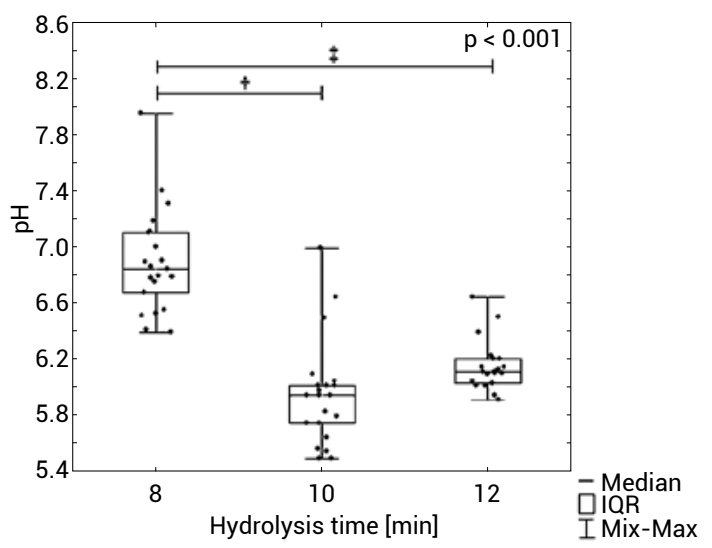

Figure 5. The influence of hydrolysis time on $\mathrm{pH}$ of $\left[{ }^{18} \mathrm{~F}\right] \mathrm{FDG}$.

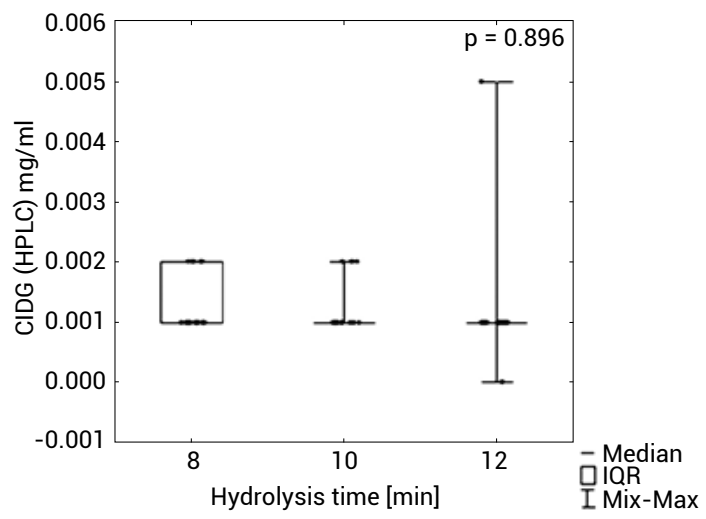

Figure 4. The influence of hydrolysis time on chemical purity, CIDG concentration $[\mathrm{mg} / \mathrm{mL}]$; HPLC method.

contamination and the correct value of the $\mathrm{pH}$ of the produced radiopharmaceutical.

The tests show that a hydrolysis time of 8 minutes is the minimum time for which the protected derivatives of $\left[{ }^{18} \mathrm{~F}\right] \mathrm{FDG}$ should be exposed to hydrochloric acid in order to disconnect the protecting groups (acetyl) in a quantity that exceeds the acceptance threshold for radiochemical purity while maintaining chemical purity and $\mathrm{pH}$ value.

Statistical analysis shows that all results obtained during the hydrolysis of 8 minutes are within the limit values for all measurement methods. However, in the case of a measurement carried out with the use of TLC, some of the results are on the acceptance/rejection threshold. It would seem that the release of the product to a patient with a borderline result is not a problem because it is within the acceptance criteria, which means that the product can be released for administration at a given moment. However, in the case of product stability testing, which consists in proving that throughout its shelflife a drug remains effective and safe for the patient, a borderline acceptance/rejection result may have an impact on the success of the test. A negative result of the test may be affected by the measurement error of the device and operator error (human).

The study proved that the change of a single synthesis parameter has a significant impact on the quality control results. This parameter is the hydrolysis time, the elongation of which has a significant effect on improving the purity of the final $\left[{ }^{18} \mathrm{~F}\right] \mathrm{FDG}$ product (Table 1, Figure 1).

Extension of the hydrolysis time to $14,16,18$, and 20 minutes, has no significant effect on the quality control results. Extending the hydrolysis time from 8 minutes to 10 and then to 12 minutes reduced the amount of partially or fully acetylated derivatives in the final product (Table 1, Figure 2). The results 
are statistically significant. The extension of the hydrolysis time did not affect the radiochemical purity (Table 1, Figure 3) and did not increase the content of 2-chloro-2-deoxy-D-glucose (chemical purity) resulting from the replacement of the ${ }^{18} \mathrm{~F}$ - anion with Cl- during the action of hydrochloric acid on mannose triflate (Table 1, Figure 5).

The prolonged time of hydrolysis had an effect on the reduction of the $\mathrm{pH}$ value (Figure 5), which was caused by the increase in the amount of acetic acid formed after the cleavage of the acetyl groups from 1,3,4,6-tetra-O-acetyl-2- $\left[{ }^{18} \mathrm{~F}\right]$ fluoro- $\beta$ $\mathrm{D}$-galactopyranose. There is a correlation between the decrease in the amount of acetylated derivatives and the decrease in the $\mathrm{pH}$ value. The $\mathrm{pH}$ value, although not reliable, may give the first indication of whether the amount of acetyl $\left[{ }^{18} \mathrm{~F}\right] \mathrm{FDG}$ impurity is high or low.

Improving the radiochemical purity while maintaining high chemical purity and the $\mathrm{pH}$ value at increasing the hydrolysis time by 4 minutes from the initial value of 8 minutes is negligible. Assuming that the average activity obtained from the cyclotron and sent to the synthesis module was $120 \mathrm{GBq}$, the decrease in activity after 4 minutes is $3 \mathrm{GBq}$.

The dose required for testing in accordance with the reference procedures for nuclear medicine is 5-7 MBq $/ \mathrm{kg}$. This means that for a patient weighing $70 \mathrm{~kg}$, the dose of radiopharmaceutical administered has an activity of 350-490 MBq, and assuming that the quality control result for acetyl derivatives was on the borderline of acceptance/rejection, the patient could receive about 17.5-24.5 MBq of impurities.

The dose of diagnostic value would be reduced by the activity of the contaminants. Acetyl impurities are hydrolyzed and metabolized in tumor cells to 2-fluoro- $\left[{ }^{18} \mathrm{~F}\right]$-2-deoxy-D-glucose and then to 2-fluoro- $\left[{ }^{18} \mathrm{~F}\right]$-2-deoxy-D-glucose-6-phosphate. They have no negative impact on the patient's health and the result of the diagnostic procedure. The mechanism of the transport of acetyl derivatives into the cell is GLUT independent. These compounds are highly lipophilic and penetrate the cell membrane by simple diffusion. Its detail of character is still unknown, but further basic, as well as clinical trials using such well-characterized tracers, will provide new perspectives in the field of oncology (11).

\section{CONCLUSIONS}

Extending the hydrolysis time significantly increased the radiochemical purity of the final product, improving its quality parameters while maintaining the chemical purity and $\mathrm{pH}$ value, and with only a slight loss of activity.

The result on the borderline of acceptance/ rejection may negatively affect the stability test. Increasing the radiochemical purity avoids the invalidation of this test due to the influence of the measurement error of the device and possible operator error (human).

Minimizing contamination reduces impact GLUT independent tumor cell accumulation of $\left[{ }^{18} \mathrm{~F}\right] \mathrm{FDG}$, which its detail of character is still unknown.

\section{Conflicts of interest}

The authors declare that there are no conflicts of interest.

\section{REFERENCES}

1. Ziegler S.I.: Nucl. Phys. A. 752, 679 (2005).

2. Goldman L.W.: J. Nucl. Med. Technol. 35, 115 (2007).

3. Vogel W.V., Oyen W.J.G., Barentsz J.O., Kaanders J.H.A.M., Corstens F.H.M.: J. Nucl. Med. 45, 15 (2004).

4. Malenda A., Nowis D.A.: Hematologia 4, 227 (2013) (in Polish).

5. Jóźwiak P., Lipińska A.: Postepy Hig. Med. Dosw. 66, 165 (2012) (in Polish).

6. Dudziak K., Regulska-Ilow B.: Postepy Hig. Med. Dosw. 67, 449 (2013) (in Polish).

7. Izuishi K., Yamamoto Y., Mori H., Kameyama R., Fujihara S., et al.: Oncol. Rep. 31, 701 (2014).

8. Ruangma A.: BKK Med. J. 5, 80 (2013).

9. Królicki L., Kunikowska J., Kobylecka M., Mączewska J., Fronczewska K.: Post. Nauk Med. 24, 104 (2011) (in Polish).

10. Jacobson O., Kiesewetter D.O., Chen X.: Bioconjugate Chem. 26, 1 (2015).

11. Waki A., Fujibayashi Y., Magata Y., Yokoyama A., Sadato N., et al.: J. Nucl. Med. 39, 245 (1998). 